\title{
Evolução dos isolamentos em doenças transmissíveis: os saberes na prática contemporânea*
}

\author{
EVOLUTION OF THE ISOLATION OF CONTAGIOUS DISEASES: \\ KNOWLEDGE IN CONTEMPORARY PRACTICE
}

EVOLUCIÓN DEL AISLAMIENTO EN LAS ENFERMEDADES TRANSMISIBLES:
LOS SABERES EN LA PRÁCTICA CONTEMPORÁNEA

\section{Lúcia Yasuko Izumi Nichiata ${ }^{1}$, Elucir Gir ${ }^{2}$, Renata Ferreira Takahashi ${ }^{3}$, Suely Itsuko Ciosak ${ }^{4}$}

\author{
RESUMO \\ A identificação de novos \\ agentes infecciosos, a \\ crescente expansão de \\ infecções e doenças já \\ conhecidas têm estimulado a \\ revisão das medidas de \\ biossegurança nas atividades \\ profissionais dos \\ trabalhadores da saúde. \\ No presente artigo recuperou- \\ se a evolução dos saberes e \\ práticas dos isolamentos/ \\ precauções, o que permitiu \\ resgatar os conceitos e as \\ intervenções que vieram \\ sendo formuladas $e$ \\ implementadas. Desde o \\ início da enfermagem \\ moderna, no século XIX, \\ mantém-se basicamente os \\ mesmos elementos da prática \\ dos isolamentos em doenças \\ transmissiveis, ou seja, \\ destaque à utilização de \\ barreiras mecânicas, \\ químicas e ambientais, \\ fundamentadas nas \\ especificidades inerentes aos \\ elementos da cadeia do \\ processo infeccioso.
}

\author{
PALAVRAS-CHAVE \\ Isolamento de pacientes. \\ Controle de doenças \\ transmissiveis. \\ Enfermagem.
}

\author{
ABSTRACT \\ The identification of new \\ infectious agents and the ever \\ increasing expansion of known \\ infections and diseases have \\ been stimulating the revision \\ of biosafety measures in the \\ activities of professional \\ health care workers. In the \\ present article, the evolution \\ of knowledge and practices \\ of isolation and precautions \\ were reviewed, which allowed \\ us to recover the concepts \\ and the interventions that \\ were formulated and \\ implemented. Since the \\ beginning of the modern \\ nursing, in the XIX century, \\ the elements of the isolation \\ practice for contagious \\ diseases have remained \\ basically the same. In other \\ words, the emphasis on the \\ use of mechanical, chemical \\ and environmental barriers \\ are given, based on inherent \\ specificities of each part of \\ the infectious chain process.
}

\section{KEYWORDS}

Isolation of patient. Contagious diseases. Nursing.

\section{RESUMEN}

La identificación de nuevos agentes infecciosos, la creciente expansión de infecciones y enfermedades ya conocidas, han estimulado la revisión de las medidas de bioseguridad en las actividades profesionales de los trabajadores de la salud. En el presente artículo, se recuperó la evolución de los saberes y de las prácticas de aislamiento/precauciones, lo que permitió rescatar los conceptos y las intervenciones que vienen siendo formuladas e implementadas. Desde el nacimiento de la enfermería moderna en el siglo XIX, se mantienen básicamente los mismos elementos de las prácticas de aislamiento en enfermedades transmisibles, es decir, predomina la utilización de barreras mecánicas, químicas y ambientales, fundamentadas en las especificidades inherentes a los elementos de la cadena del proceso infeccioso.

\section{PALABRAS CLAVE}

Aislamiento de pacientes. Enfermedades transmisibles. Enfermería.

\author{
* Resultados parciais do \\ Projeto "A enfermagem \\ e o uso do isolamento \\ em doenças \\ transmissíveis: da \\ teoria à prática", \\ desenvolvido com o \\ apoio financeiro da \\ Fundação de Amparo à \\ Pesquisa do Estado de \\ São Paulo (FAPESP). \\ 1 Professor Doutor do \\ Depto de Enfermagem \\ em Saúde Coletiva \\ da Escola de Enferma- \\ gem da USP (EEUSP). \\ izumi@usp.br \\ 2 Professor Associado \\ junto ao Departamento \\ de Enfermagem Geral \\ e Especializada da \\ Escola de Enferma- \\ gem de Ribeirão Preto \\ da USP (EERP/USP). \\ egir@eerp.usp.br \\ 3 Professor Doutor do \\ Depto de Enfermagem \\ em Saúde Coletiva \\ da EEUSP. \\ rftakaha@usp.br \\ 4 Professor Doutor do \\ Depto de Enfermagem \\ em Saúde Coletiva \\ da EEUSP. \\ siciosak@usp.br
}


Lúcia Yasuko I. Nichiata Elucir Gir

Renata Ferreira Takahashi Suely Itsuko Ciosak

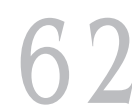

Rev Esc Enferm USP 2004; 38(1): 61-70.

\section{INTRODUÇÃO}

O acometimento de trabalhadores da saúde por infecções e doenças transmissíveis decorrente de suas atividades profissionais vem se constituindo como um importante problema enfrentado pelas instituições de saúde. Em virtude de suas atividades ocupacionais estes encontram-se expostos a diferentes agentes patogênicos veiculados através do sangue ou outros líquidos orgânicos de pacientes potencialmente contaminados. Como exemplos destaca-se, a infecção pelo Human Immunodeficiency Virus (HIV), cujo risco para se adquirir o vírus após exposição percutânea ao sangue contaminado é estimado em $0,3 \%$, podendo chegar a $1 \%$ ou $2 \%$ dependendo da categoria profissional envolvida. Outra infecção importante é a decorrente do vírus da hepatite $\mathrm{B}$, cuja situação é ainda mais alarmante, pois estima-se que o risco chega a $30 \%$, quando nenhuma medida profilática é adotada ${ }^{(1)}$.

Nos Estados Unidos, até 1995 já haviam sido identificados cerca de 1000 trabalhadores da saúde contaminados com o vírus da hepatite $\mathrm{C}$ (HCV), estimando-se ainda que a cada ano ocorram cerca de 1000 casos novos de hepatite $\mathrm{B}$ nessa população ${ }^{(2)}$. Decorrente de suas atividades ocupacionais já foram docu-mentados 56 casos de contaminação pelo HIV ${ }^{(3)}$.

No Brasil, as estatísticas de contaminação pelas hepatites virais, pelo HIV e pela tuberculose entre trabalhadores da saúde após acidentes, são escassas. Quanto a aids, o Sistema de Vigilância Epidemiológica identifica como primeiro caso no Município de São Paulo, uma soroconversão após o acidente ocupacional envolvendo agulha contaminada com sangue, ocorrido em 1994, com uma auxiliar de enfermagem ${ }^{(4)}$. Para a tuberculose, um estudo realizado em São Paulo revelou que a prevalência da doença entre trabalhadores em hospitais era quatro vezes maior que a da população geral do Estado ${ }^{(5)}$.

Reconhece-se que, pode ocorrer uma subnotificação dos casos, dado a extensão com que ocorre os acidentes envolvendo material biológico, junto aos trabalhadores da área da saúde. No Estado de São Paulo, o Sistema de Vigilância de Acidentes com Material Biológico em Profissionais de Saúde recebeu de dezembro de 1999 a agosto de 2003, 3513 notificações de acidentes, dos quais $86 \%$ das exposições foi do tipo percutâneo e $82 \%$ envolvendo sangue, sendo que até o momento não foram relatados soroconversão ao HIV, HBV ou HCV, relacionados à esses acidentes. Destes, a maioria estava relacionada aos trabalhadores da enfermagem (58\%), seguido dos funcionários da limpeza $(8,3 \%)$ e médicos $(7,0 \%)^{(6)}$.

Os dados mostram que, dentre os trabalhadores da saúde, a enfermagem está mais sujeita aos acidentes ocupacionais, envolvendo material biológico contaminado. Analisando 2344 acidentes notificados, num hospital universitário no Município de São Paulo, entre 1992 e 2001, verificou-se que em $41 \%$ dos acidentes estiveram envolvidos enfermeiros e auxiliares de enfermagem, enquanto que médicos e residentes totalizaram $36 \%{ }^{(7)}$. Num outro estudo realizado também num hospital universitário do mesmo município, do total de 1395 acidentes com agulhas, ocorridos de 1990 a 1996, identificou-se 584 (41,9\%) acidentes somente com a equipe de enfermagem, os demais $(58,1 \%)$ congregavam seis categorias profissionais diferentes ${ }^{(8)}$.

A expressiva vulnerabilidade da equipe de enfermagem à exposição aos acidentes pode ser explicada por ser este o contingente mais numeroso da força de trabalho em saúde, com formação técnica muito heterogênea, nem sempre contemplada na divisão do trabalho, ministrando cuidados que, em sua maioria, envolvem o contato direto com o doente, fazendo parte de um grupo social que enfrenta desgastes dos mais variados, em decorrência de sua condição de vida e trabalho ${ }^{(9)}$.

Ao mesmo tempo, são estes que têm dificuldades em aderir às medidas de segurança que busquem a proteção ao risco de exposição, subestimando muitas vezes o próprio risco ${ }^{(10-11)}$.

A adesão às ações de biossegurança constitui o maior desafio, desde as primeiras formulações das medidas de proteção, inicialmente referidas como isolamentos. A despeito do desenvolvimento e emprego da tecnologia dos materiais utilizados em serviços de saúde, em especial os descartáveis e das técnicas e procedimentos recomendados na prevenção das infecções e das doenças transmissíveis, não se tem conseguido a redução das ocorrências das 
infecções e das doenças entre os trabalhadores. Considerando que a adoção (ou não) das medidas de biossegurança na atualidade estão ancoradas nas concepções sobre saúde e doença que vêm sendo construídas ao longo da história humana, buscou-se fazer uma recuperação histórica da evolução dos saberes e práticas dos isolamento/ precauções, o que permitiu o resgate das mudanças de conceitos formulados no passado e das intervenções construídas, identificar a origem das práticas atuais de isolamento e a permanência de saberes na prática contemporânea.

\section{BREVE RETROSPECTIVA SOBRE A EVOLUÇÃO DAS PRÁTICAS DE PRECAUÇÕES/ISOLAMENTO}

A concepção e a prática de precauções/ isolamento como um instrumental de intervenção na prevenção e controle das doenças transmissíveis estão atreladas ao avanço do conhecimento científico e aos significados atribuídos pelas sociedades à saúde e à doença, ao longo da história da humanidade.

Para a apreensão dos princípios que hoje norteiam essa prática é necessário resgatar a história das doenças contagiosas. A sua existência é descrita desde a Antigüidade, época das grandes epidemias que assolaram a Europa, como a lepra e a peste negra. Canguilhem ${ }^{(12)}$ considera que até o século XIX coexistiam duas concepções de doença, a ontológica e a dinâmica. Na primeira delas a doença era compreendida como algo externo ao homem, que não fazia parte da natureza humana e sua origem poderia ser natural ou sobrenatural, como o ar, objetos ou outros indivíduos. Enraizada nessa concepção, formou-se a representação da doença como um castigo dos deuses para a impureza espiritual humana, que com o aparecimento da aids, emergiu com força no imaginário social, especialmente no início da epidemia, quando o conhecimento disponível acerca da síndrome era ainda insuficiente para explicar a sua causalidade ${ }^{(13)}$.

Conforme afirma Canguilhem ${ }^{(12)}$, a prática decorrente do pensamento vigente na época, tinha a cura como um “...esforço de expulsão da doença por meio de tratamentos mágicos...", postura por assim dizer, "contemplativa", no sentido de que a ação terapêutica se baseava na expectativa de que a natureza se incumbiria da cura. Até então, o isolamento tinha como propósito proteger o corpo de influências maléficas de distintas origens, como os miasmas, as influências astrológicas e divinas, ainda relacionadas a origem das doenças ${ }^{(14)}$.

Na concepção dinâmica, a doença era resultante de um desequilíbrio ou uma desarmonia entre as forças vitais, compre-endia um processo que ocorria no interior do homem, que poderia também advir de um desarranjo do equilíbrio dos quatro humores presentes no planeta: a terra, o ar, a água e o fogo ${ }^{(12)}$. Já havia a noção de contágio, constatado na observação daqueles que adoeciam após o cuidado dos doentes. Nos séculos XIV e XV esse conceito foi se ampliando conforme evidenciam as práticas desse período, como o uso de máscaras, a fumigação, adotados com o intuito de evitar a aspiração de odores poluidores do ar. Segundo o autor, existia a suspeita de que as pessoas sadias eram contagiados não só pela proximidade com o enfermo, mas também pelo ato de conversar, de tocar roupas ou qualquer objeto que tivesse sido manipulado pelo doente ${ }^{(15)}$.

Fracastoro no século XVI foi quem melhor formulou uma teoria para explicar a origem das doenças epidêmicas, em que definia contágio como

uma corrupção precisamente similar em ambos, portadores e receptores, causada por infecção de partículas imperceptíveis, denominadas semminaria,

transmitidas de forma direta através da pele, ou indireta por meio de objetos ou ainda à distância sem mediação. A principal contribuição do médico italiano foi buscar a identificação de um princípio, uma causa para a origem da doença e não mais considerá-la como resultante de um desequilíbrio do corpo humano ou da natureza ${ }^{(15)}$.

Nessa fase da história foram instituídos o exílio e a exclusão dos doentes do convívio em sociedade, comportamentos que deram origem às práticas de isolamento, algumas das quais permanecem até os dias atuais. Exemplo disso é a quarentena, que consistia na instituição de um período de 40 dias de contenção dos navios que chegavam de regiões epidêmicas, atracados nos portos, bem como seus tripulantes e mercadorias. Assim, as pessoas eram afastadas da convivência para observar se apresentavam ou não doença ${ }^{(16)}$.
Evolução dos isolamentos em doenças transmissíveis: os saberes na prática contemporânea 
Lúcia Yasuko I. Nichiata Elucir Gir

Renata Ferreira Takahashi Suely Itsuko Ciosak
No final do século XVIII, com o desenvolvimento da bacteriologia e da microbiologia e o nascimento da clínica, começa a surgir a idéia de transmissão, uma verdadeira mudança na compreensão da causa da doença, pois passam a ser identificados os agentes microbiológicos, ampliando, inclusive, as possibilidades de intervenção terapêutica. Conhecer a doença passou a ser o desvendamento de uma ocorrência orgânica que se produz no espaço do corpo. Através da observação e experimentação, a busca por uma causa passa a ser precisa e rigorosa,

a racionalidade científica médica se estruturou na explicação dos fenômenos com base no estudo de mudanças morfológicas, orgânicas e estruturais ${ }^{(15)}$.

Dessa forma,

a medicina desenvolveu recursos objetivamente capazes de intervir na sobrevida do homem e na sua impotência em relação à doença,

suscitando inclusive abordagens bastante otimistas em relação ao banimento das grandes epidemias ${ }^{(15)}$.

Os conceitos e técnicas que emergiram com a bacteriologia e microbiologia modificaram as concepções sobre a saúde e a doença e, portanto, as formas de intervir sobre elas. Um bom exemplo disso é a conformação dos hospitais como local privilegiado para a observação e a aplicação dos conhecimentos desenvolvidos até então e como estes passaram a incorporar as medidas de isolamento/ precauções à sua prática.

\section{AS PRÁTICAS DE ISOLAMENTO NO HOSPITAL}

O hospital na sua origem não foi constituído como um local privilegiado da prática médica, funcionava muito precariamente, como abrigo para os peregrinos, pobres, inválidos e doentes, exercido por leigos, principalmente religiosos e, paradoxalmente, por proscritos que pagavam penitência. Por sua vez, o cuidado propriamente com os doentes era exercido pelos familiares nos seus domicílios ${ }^{(14)}$. A finalidade do hospital, passando a ser um local de assistência aos doentes só ocorreu impulsionado pelo desenvolvimento do capitalismo industrial. Dessa forma foram construídos os hospitais gerais, primeiro em Londres, expandindo para outras localidades, no sentido de tornar acessível estes serviços de saúde ao conjunto da população, vistos como o mais importante recurso produtivo de uma nação. Era imperativo reduzir a mortalidade causada pelas grandes epidemias e, ao mesmo tempo, redefinir a função dos hospitais, que passaram a assumir papel importante na recuperação da força de trabalho ${ }^{(17)}$. Conforme analisa Foucault, a preocupação com a salvação da alma é substituída pela preocupação com a saúde dos corpos, que adquiriu importância enquanto instrumento essencial do processo de acumulação do capital ${ }^{(17)}$.

De abrigo aos excluídos da sociedade à nova formulação, o hospital sofreu modificações. As condições de higiene nos hospitais eram precárias e a prática de enfermagem era realizada ainda de forma muito rudimentar. As primeiras tentativas de sistematizar e estruturar uma melhoria da qualidade no interior dessas instituições foram realizadas na França. Howard, médico designado pela Academia de Ciências da França percorreu os hospitais da Europa, documentou e denunciou condições de maus tratos aos doentes, oferecendo subsidíos para um programa de reformas e reorganização do trabalho nesses locais ${ }^{(17)}$.

Os relatos sobre o início das práticas de isolamento pela enfermagem são escassos. Em 1863, Florence Nightingale, fundadora da escola de enfermeiras em Londres e reconhecida como marco na chamada "enfermagem moderna", estabeleceu as primeiras recomendações sistematizadas relacionadas ao cuidado do paciente, enfatizando a necessidade de limpeza do ambiente hospitalar ${ }^{(18)}$. Em consonância com os conhecimentos produzidos até aquele momento, os ensinamentos de Nightingale concebiam a transmissão de doenças por substâncias do corpo e a intervenção voltavase para o ambiente hospitalar, como cuidados em relação ao ar puro, luz, calor, limpeza, enfatizando a necessidade de separação dos doentes infectados dos não infectados ${ }^{(18)}$.

Somente com o estabelecimento de uma causa microbiológica da doença, através da demonstração experimental feita por Pasteur e Koch, entre 1877 a 1897 , houve novas possibilidades de formulações teóricas e novas intervenções sobre a questão do controle das doenças infecciosas. O desenvolvimento nos conhecimentos da bacteriologia, da imunologia, e da epidemio- 
logia propiciaram a formulação dos conceitos até hoje consagrados, tais como, infectividade, virulência e patogenicidade, relacionados ao microorganismo produtor de infecção e doença. Definiram-se ainda, as propriedades dos hospedeiros, conceituando suscetibilidade e resistência. E talvez o mais importante, estabeleceu explicação sobre modos de transmissão, isto é, vias e condições pelas quais os microorganismos penetram no organismo, conhecido como "cadeia do processo infeccioso" (15).

O avanço no conhecimento científico impulsionou a adoção de novas tecnologias e intervenções como a assepsia, anti-sepsia, desinfecção, esterilização, antibioticoterapia e diferentes formas de isolamento. Nessa época, os agentes biológicos constituiam risco real ou potencial para o homem, especialmente durante o cuidado do doente nos hospitais, como relata a publicação em 1885 sobre o a contaminação de um profis-sional por Salmonella typhi, em um laboratório na Alemanha. Em 1903 relatouse a primeira infecção adquirida por um médico em laboratório nos Estados Unidos, após acidente com agulha ${ }^{(19)}$

Estas descobertas e inúmeros outros relatos sobre contaminação profissional que se seguiram, recolocaram a questão dos isolamentos/precauções, no sentido de que as recomendações passaram a ser desenvolvidas visando evitar a transmissão de microorganismos patogênicos, não só para outros pacientes, mas passaram a ser pensados também em relação aos trabalhadores da saúde.

A organização Mundial da Saúde e a Organização Panamericana de Saúde em 1960 definiu o isolamento como

\begin{abstract}
a segregação de pessoas infectadas, durante o período de transmissiblidade da doença, em local sob condições para evitar a transmissão direta ou indireta do agente infeccioso a indivíduos suscetíveis, ou que possam transmitir a outros ${ }^{(20)}$.
\end{abstract}

No Manual para el Controle de las Enfermedades Transmissíveis, uma publicação da OPAS, o isolamento é referido como uma medida de controle do paciente, seus contatos e ambiente e inclui medidas destinadas a evitar que o indivíduo infectado siga disseminando a doença ${ }^{(21)}$.

Segundo o Centro Latino-Americano e do Caribe de Informação em Ciências da Saúde da Organização Panamericana de Saúde, Bireme, o descritor isolamento de pacientes tem como definição a restrição dos movimentos e dos contatos sociais, onde é feito um esforço para controlar aspectos específicos do cuidado de pacientes com doenças transmissíveis, para prevenir um contágio, por um tempo determinado; ou quando o paciente é isolado em um ambiente controlado ou isento de germes, para sua proteção à alguma contaminação ${ }^{(22)}$.

\section{A INCORPORAÇÃO DOS SABERES NA PRÁTICA DE ISOLAMENTO NO BRASIL}

No Brasil, o primeiro hospital de isolamento, o Hospital Emílio Ribas foi fundado em 1890 e tinha como recomendação para evitar e controlar as doenças dentro do ambiente hospitalar, a adoção de medidas, conhecida como "cordão hospitalar", isolando os pacientes com doenças advindas da comunidade, como a difteria, tuberculose e varíola, preconizando a separação de indivíduos portadores de doenças comuns, em pavilhões, cada um deles servido por pessoal e material próprio, evitando assim contato entre pacientes com a mesma patologia. Naquele momento, não havia ainda a preocupação com a infecção hospitalar, do modo como a entendemos hoje ${ }^{(14)}$.

A demanda por hospitais gerais foi crescendo e a necessidade de maior número de leitos destinados a pacientes com doenças transmissíveis fizeram rever a lógica de constituição dos grandes hospitais de isolamento. Nos Estados Unidos, em 1910, criouse o "sistema de compartimento de isolamento", uma série de medidas que possibilitou aos hospitais a abertura de leitos e enfermarias para o tratamento das doenças transmissíveis, antes restritas aos de isolamento. As medidas diziam respeito à utilização de equipamentos e materiais separados para cada paciente, como roupas próprias para a realização dos procedimentos utilizados pelos trabalhadores e recomedação quanto a higienização das mãos após o contato com o paciente e a desinfecção do equipamento contaminado ${ }^{(23)}$. De fato, a partir da década de 1950, os hospitais de isolamento para doenças infecciosas dos Estados Unidos começam a ser desativados.

Os Centers for Disease Control and Prevention (CDC) dos Estados Unidos publicou um manual em 1970 detalhado sobre "Técnicas para isolamento em hospitais" com
Evolução dos isolamentos em doenças transmissíveis: os saberes na prática contemporânea 
Lúcia Yasuko I. Nichiata Elucir Gir

Renata Ferreira Takahashi Suely Itsuko Ciosak

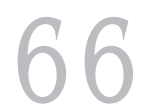

Rev Esc Enferm USP 2004; 38(1): 61-70. o objetivo de fornecer orientações aos hospitais gerais sobre a utilização das precauções para o isolamento de pacientes com infecções e doenças transmissíveis ${ }^{(24)}$. Revisado e novamente publicado em 1975, o manual recomendava uma classificação de sete categorias de isolamento, conforme as vias de transmissão das doenças. Como equipamentos de proteção individual (EPI) preconizava-se o uso de luvas, avental e máscaras, a depender do tipo de categoria.

Tais recomendações nortearam as ações no âmbito da assistência ao portador de doenças transmissíveis em praticamente todos os hospitais americanos durante cerca de uma década e foram adotadas por hospitais de diferentes países, inclusive o Brasil.

Nos Estados Unidos, no período de 1981 a 1983, consultando especialistas em doenças infecciosas no setor médico pediátrico, cirúrgico, epidemiologistas e peritos de controle de infecção, os CDC realizaram nova revisão das normas de isolamento e precauções, instituindo as seguintes categorias: Isolamento Rigoroso/Estrito, Respiratório, de Contato, da Tuberculose, Precauções Entéricas, com Secreções Drenadas e com Sangue e Fluidos Corpóreos ${ }^{(25)}$

Em 1985, os CDC revisaram novamente as orientações sobre isolamento eliminando a categoria precaução com sangue e secreções, substituindo-a pelas precauções universais, por considerarem que a anamnese e o exame físico não permitiam identificar confiavelmente todos os portadores do HIV e outros patógenos transmitidos por sangue e fluidos corporais ${ }^{(26)}$. Mais uma vez, em 1987, os CDC propuseram uma nova categoria de isolamento denominada Isolamento de Substâncias Corpóreas (ISC), ampliando as recomendações denominadas precauções universais, incluindo qualquer substância corpórea úmida de todos os usuários de serviços de saúde, sem considerar o seu estado de infecção presumida. Passaram a ser considerados potencialmente infectantes o sangue, as fezes, a urina, o escarro, a saliva, o conteúdo de drenagem de feridas e outros fluidos corpóreos. As vantagens dessa classificação residiam no fato dela ser mais abrangente, de fácil aprendizado e operacionalização, ainda que tivesse como desvantagens o custo adicional pelo uso ampliado de equipamentos de proteção individual (EPI), particularmente as luvas. Havia porém a dificuldade de adesão a ela, como uma rotina na prestação da assistência, pelos profissionais que a interpretavam como uma prática promotora de proteção excessiva e desnecessária.

Vale ressaltar que estas mudanças foram necessárias dadas a situação epidemiológica que se apresentava na época. No Brasil, somente em 1985, o Ministério da Saúde publicou o Manual de Controle de Infecção Hospitalar, contendo recomendações específicas para a prática de isolamento nos hospitais brasileiros, com base nas recomendações do CDC definidas em $1970^{(27)}$. Foram reproduzidas as sete categorias de isolamento tendo como eixo norteador o diagnóstico (suspeito ou confirmado), a forma de transmissão do agente e o período de transmissibilidade, que permitiam definir, respectivamente, o tipo de isolamento, as "barreiras" a serem adotadas e o tempo de duração do isolamento. Os isolamentos criados foram denominados de: isolamento total ou estrito, respiratório, reverso ou protetor, precauções entéricas, com pele/feridas, com sangue e com secreções/excreções ${ }^{(23)}$.

Além disso, o Ministério da Saúde definiu cuidados específicos para a prevenção da transmissão do HIV para profissionais da área da saúde. Estas orientações baseavam-se na premissa de que todos os pacientes são potenciais fontes de infecção e, em função disso, devem ser utilizadas barreiras para impedir a disseminação desses agentes infecciosos aos trabalhadores da saúde, através do contato com fluidos orgânicos dos pacientes na prestação da assistência.

Apesar da adoção de práticas de isolamento, intensificada na década de 80 , os hospitais brasileiros vinham se defrontando com infecções nosocomiais endêmicas e epidêmicas, decorrentes principalmente dos microorganismos multiresistentes a medicamentos. Ao mesmo tempo, o surgimento e a rápida disseminação da aids, associado ao aumento do número de casos de hepatites virais, incrementou a discussão em torno de medidas mais eficazes de controle dessas infecções através da prática das precauções e do isolamento.

O isolamento para substâncias corpóreas e as precauções universais compartilhavam algumas configurações indicadas para prevenir a transmissão de patógenos veiculados pelo sangue em hospitais. Admitindo que o sangue era a fonte 
de contaminação mais importante e reconhecendo a importância de todos os fluidos corpóreos, secreções e excreções na transmissão de origem nosocomial, sentiu-se a necessidade de uma nova política de isolamento com maior ressonância epidemiológica. Esta deveria incluir as precauções adequadas para as infecções veiculadas pelo ar, transmitidas por gotículas e por contato, ser tão simples quanto possível para o usuário e usar uma terminologia nova para evitar confusão com os sistemas existentes ${ }^{(23)}$.

Baseado nessas considerações os CDC instituíram as precauções padrão que são indicadas para reduzir os riscos de transmissão de patógenos em hospitais ${ }^{(23)}$. Mudanças importantes foram introduzidas em relação às recomendações anteriores: as precauções padrão incorporaram as precauções universais e o isolamento para substâncias corpóreas, ampliando-as. As precauções padrão aplicamse a todas as situações quando houver a possibilidade de exposição a todos os fluídos corporais, secreções e excreções, quer contenham sangue ou não, à pele com solução de continuidade e às membranas mucosas ${ }^{(23)}$. Nessa situação recomenda-se a utilização de máscaras, óculos, luvas e avental como barreiras para evitar a contaminação.

Em conjunto com as precauções padrão, foram estabelecidas as precauções baseadas na transmissão, indicadas para pacientes comprovadamente infectados, ou suspeitos de sê-los, com patógenos altamente transmissíveis ou epidemiologicamente importantes para os quais medidas adicionais às precauções padrão são necessárias para interromper a transmissão nos hospitais. Há três tipos de precauções baseadas na transmissão: Precauções aéreas, Precauções por gotículas e Precauções por contato. Quer usadas isoladamente ou combinadas, pressupõem sempre o uso simultâneo das precauções padrão ${ }^{(23)}$.

As precauções aéreas são indicadas para reduzir o risco de transmissão de agentes infecciosos veiculadas pelo ar (partículas residuais pequenas, com $5 \mathrm{~mm}$ ou menos) provenientes de gotículas evaporadas e que podem permanecer em suspensão no ar por longo período de tempo ou de partículas de poeira contendo um agente infeccioso. Os microorganismos carregados dessa forma podem ser dispersos para longe, pelas correntes de ar e podem ser inalados ou depositados em um hospedeiro suscetível, dentro do mesmo quarto ou a longa distância do paciente-fonte, dependendo dos fatores ambientais. Por esse motivo, exige-se a circulação do ar e ventilação especiais para prevenir a transmissão por via aérea. As precauções aéreas aplicam-se aos patógenos conhecidos que podem ser assim transmitidos, o que inclui o bacilo da tuberculose, o vírus do sarampo e o da varicela ${ }^{(23)}$. Nesse tipo de precaução indica-se o uso máscaras especiais com maior poder de filtragem e quando houver possibilidade de contato com secreções, aventais e máscaras.

As precauções por gotículas são indicadas para evitar o risco de transmissão de agentes infecciosos veiculados por vias aéreas, através de contato com a conjuntiva e com a mucosa do nariz ou da boca de um indivíduo suscetível com gotículas de tamanho grande (maior do que $5 \mathrm{~mm}$ ), originadas de um indivíduo-fonte, sobretudo durante a tosse, o espirro ou conversa e durante a realização de certos procedimentos, como a sucção ou a broncoscopia. A transmissão de gotículas de tamanho grande requer um contato mais próximo entre $o$ indivíduo-fonte e o receptor, porque não permanecem suspensas no ar e geralmente se espalham através dele, a uma distância de aproximadamente um metro ${ }^{(23)}$. Como exemplo de infecções e doenças que exigem essas precauções tem-se a meningite meningocócica, a meningite por Haemo-philus influenzae, as pneumonias e as difterias em geral. Como equipamentos de proteção individual é indicado o uso de máscaras comuns e quando houver contato com secreções, o avental e a luva.

As precauções por contato visam impedir o risco de transmissão de agentes epidemiologicamente importantes, por contato direto ou indireto. Este tipo de transmissão envolve o contato pele a pele e a transferência física proveniente de indivíduo infectado ou colonizado por microorganismo para um hospedeiro suscetível, tal como ocorre quando o profissional muda o paciente de posição, dálhe banho ou realiza atividades de atendimento que exigem o contato físico. Pode ocorrer também entre dois pacientes, pelo contato das mãos. As doenças que são transmitidas por contato incluem as gastroenterites, o impetigo, a pediculose, a escabiose, a herpes simples/viral e zoster, a furunculose infantil, a difteria cutânea e a hepatite $\mathrm{A}^{(23)}$. Para este tipo de precauções é indicado a utilização de luvas e avental.
Evolução dos isolamentos em doenças transmissíveis: os saberes na prática contemporânea 
Lúcia Yasuko I. Nichiata Elucir Gir

Renata Ferreira Takahashi

Suely Itsuko Ciosak
No Quadro 1 apresentado a seguir encontram-se representados cinco grupos de categorias de isolamento utilizados desde a década de 70 até hoje ${ }^{(28-35)}$.

Quadro 1 - Categorias de isolamento/precauções, segundo o ano de publicacação das recomendações (Brasil, 1970 a 1999)

\begin{tabular}{|c|c|c|c|c|}
\hline 1970 & 1975 & 1983 & 1987 & 1996 \\
\hline $\begin{array}{l}\text { 1. Isolamento total } \\
\text { ou escrito } \\
\text { 2. Isolamento } \\
\text { respiratório } \\
\text { 3. Isolamento } \\
\text { protetor ou } \\
\text { reverso } \\
\text { 4. Precauções } \\
\text { entéricas }\end{array}$ & $\begin{array}{l}\text { 1. Isolamento estrito } \\
\text { 2. Isolamento } \\
\text { respiratório } \\
\text { 3. Isolamento } \\
\text { protetor ou } \\
\text { reverso } \\
\text { 4. Precauções } \\
\text { entéricas } \\
\text { 5. Precauções com } \\
\text { pele/feridas } \\
\text { 6. Precauções com } \\
\text { secreções } \\
\text { 7. Precauções com } \\
\text { sangue }\end{array}$ & $\begin{array}{l}\text { 1. Isolamento estrito } \\
\text { 2. Isolamento } \\
\text { respiratório } \\
\text { 3. Isolamento para } \\
\text { tuberculose } \\
\text { 4. Precauções } \\
\text { entéricas } \\
\text { 5. Isolamento de } \\
\text { contato } \\
\text { 6. Precauções com } \\
\text { secreções e } \\
\text { drenagem } \\
\text { 7. Precauções com } \\
\text { sangue e fluídos } \\
\text { corporais }\end{array}$ & $\begin{array}{l}\text { 1. Isolamento estrito } \\
\text { 2. Isolamento } \\
\text { respiratório } \\
\text { 3. Isolamento para } \\
\text { tuberculose } \\
\text { 4. Precauções } \\
\text { entéricas } \\
\text { 5. Isolamento de } \\
\text { contato } \\
\text { 6. Precauções } \\
\text { Universais (PU) }\end{array}$ & $\begin{array}{l}\text { 1. Precauções } \\
\text { Padrão (PP) } \\
\text { 2. Precauções } \\
\text { baseadas na } \\
\text { forma de } \\
\text { transmissão: } \\
\text { 2.1 precauções co } \\
\text { aerosóis } \\
\text { 2.2 precauções por } \\
\text { gotículas } \\
\text { 2.3 precauções por } \\
\text { contato }\end{array}$ \\
\hline
\end{tabular}

No Brasil, enfrenta-se inúmeras dificuldades para divulgar de forma rápida e atualizada as informações e o conhecimento produzido sobre isolamento/precauções pelas Secretarias de Saúde dos Estados e Municípios. Isto traz como consequência um descompasso entre as pesquisas e publicações e as práticas de isolamento efetivamente adotadas no âmbito hospitalar. Conforme analisa Arantes ${ }^{(35)}$, somente em 1985 o Brasil conseguiu incorporar as recomendações norte-americanas, datadas de 1975. Portanto, sob quais bases as instituições realizaram sua prática de isolamento nesse intervalo de 15 anos?

As autoridades de saúde do Brasil, devido às alterações epidemiológicas e clínicas de algumas doenças transmissíveis, têm procedido a revisão das recomendações sobre isolamento/precauções, entretanto, somente vem fazendo para algumas delas, como a tuberculose, as hepatites $\mathrm{B}$ e $\mathrm{C}$ e a infecção pelo HIV/AIDS, buscando alertar os profissionais da área da saúde quanto ao aumento do risco de exposição ocupacional decorrentes de tais mudanças. Mais recentemente, algumas publicações ${ }^{(30-31)}$ têm se detido na revisão das recomendações em relação ao isolamento das demais infecções e doenças, como aquelas nas ocasiões em que o paciente apresenta doença transmissível, comprovada ou suspeita, e/ou colonização por germes multiresistentes.
Na década de 90, o Ministério da Saúde e as Secretarias da Saúde de alguns Estados têm publicado uma série de Portarias para regularizar, orientar e asseguar o cuidado em relação às infecções hospitalares de um modo geral e, especificamente relacionado aos cuidados de isolamento, tendo como base as orientações do CDC. A abrangência limitada dessas publicações em relação a sua divulgação restrita, pode ser um dos motivos da manutenção de práticas inadequadas de isolamento/precauções, decorrentes do seguimento de recomendações desatuali-zadas, o que remete a uma urgente revisão e atualização das recomendações emitidas por tais órgãos em nosso país, visando contribuir para uma efetiva prevenção e controle da disseminação das doenças transmissíveis.

$\mathrm{Na}$ prática observa-se que os hospitais adotam classificações para os isolamentos bastante heterogêneas, o que pode ser constatado nas rotinas e orientações elaboradas por equipes multiprofissionais e nas diferentes publicações que versam sobre o assunto. Podese afirmar que há uma ampla divulgação em relação às recomendações sobre precauções padrão, ao mesmo tempo, nas instituições hospitalares as recomendações específicas em casos de doenças ou infecções transmissíveis ainda é freqüente a adaptação e utilização das sete categorias de isolamento do Ministério da Saúde ${ }^{(36)}$.

Embora tenha-se investido em sucessivas reformulações, não só na nomenclatura das categorias de classificação dos tipos de 
isolamento, mas também nas diferentes abordagens decorrentes da descoberta de novas doenças e suas formas de transmissão, verifica-se que os princípios que norteam os isolamentos junto às doenças transmissíveis não sofreram grandes modificações, desde as primeiras medidas adotas por Florence Nightingale e a identificação dos agentes infecciosos. O resgate das mudanças de conceitos formulados no passado e das intervenções construídas permitem identificar a origem e a incorporação de saberes na prática contemporânea. Tem como finalidade a prevenção da disseminação dos agentes causais, evitando a ocorrência da infecção/ doença, através da utilização de barreiras mecânicas, químicas e ambientais. Os tipos de precauções hoje recomendados, fundamentam-se nas especificidades inerentes aos elementos do processo infeccioso.

\section{CONSIDERAÇÕES FINAIS}

A descoberta dos agentes microbianos trouxe como contribuição a compreensão sobre a produção das doenças transmissíveis auxiliando no desenvol-vimento de medidas de proteção mais eficazes, como os isolamento/precauções.

As ocorrências de acidentes envolvendo os profissionais de saúde e a efetiva contaminação por doenças transmissíveis de alguns deles, evidencia pontos vulneráveis na abordagem da questão na prática das precauções/isolamento. A adoção de medidas de segurança pelos trabalhadores da saúde é um dos pontos nevrálgicos desta questão. Há a aceitação teórica das normas de biossegurança por todos, no entanto, ainda não se conseguiu que elas permeiem a prática diária com a mesma intensidade. Valores diferenciados são atribuídos ao risco de contaminação, conforme a categoria profissional, a atividade executada e o tempo de experiência na assistência, de modo que, embora haja consenso quanto à existência do risco, o mesmo não se aplica quanto ao "tipo" de risco.

Apesar da potencialização do risco de exposição dos trabalhadores de enferma-gem, nossa vivência no ensino, na pesquisa e extensão, tem mostrado que a adesão desses trabalhadores às medidas de proteção é pouco usual e, com freqüência, incompleta e descontínua, o que resulta em uma "falsa" proteção. Ainda que a existência do risco seja eminente, não se conseguiu que as medidas de segurança sejam incorporadas à prática dos trabalhadores da saúde, pois envolve a percepção do risco para o indivíduo. Basicamente os conceitos e as práticas dos isolamentos/precauções na atualidade são as mesmas formuladas no passado ocorrendo o mesmo com as abordagens educacionais que visam a mudança desejada.

\section{REFERÊNCIAS}

(1) CDC. Center for Disease Control. Guidelines for prevention of transmission of human immnunodeficiency virus and hepatitis B virus to health care and public safety workers. Morb Mortal Wkly Rep 1989; 38(43):746.

(2) Occupational Safety and Health Admi-nistration. Safer needles devices: protecting health care workers; 1997. Available from <http://www.oshaslc.gov/SLTC/needlestick /saferneedledevices/ saferneedledevices.html.> (18 sep. 2001)

(3) U.S. Public Health Service. Update U.S. Public Health Service Guidelines for the management of occupational exposures to HBV, HCV, and HIV and recomendations for postexposure profhylaxis. Morb Mortal Wkly Rep 2001; 50(RR-11):1-52.

(4) Santos NJS, Monteiro ALC, Ruiz EAC. The first case of aids due to occupational exposure in Brazil. Braz J Infect Dis 2002; 6(3):140-1.

(5) Bedrikow B, Justiniano JÁ, Jafferian PA, Morrasc LC, Santos MAS. Freqüência da tuberculose entre funcionários de uma instituição de assistência médica e os resultados parciais de um programa de controle. Rev Bras Saúde Ocup 1977; 5:(20): 30-3.
(6) Boletim Epidemiológico-AIDS/SP. Secretaria de Estado da Saúde de São Paulo. Programa Estadual de DST/AIDS 2002; 1(2).

(7) Coutinho AP, Verotti MP, Martins ST, Parreira FP, Destra AS, Sassi SJG et al. Epidemiologia dos acidentes com material biológico em um hospital universitário. In: Anais do $8^{\circ}$ Congresso Brasileiro de Controle de Infecção e Epidemiologia Hospitar; 2002 set 4-7; Curitiba: ABEN; 2002.

(8) Brevidelli MM, Cianciarullo TI. Análise dos acidentes com agulhas em um hospital universitário: situações de ocorrência e tendências. Rev Latino-Am Enferm 2002; 10(6):780-6.

(9) Gir E, Costa FPP, Silva AM. A enfermagem frente a acidentes de trabalho com material potencialmente contaminado na era do HIV. Rev Esc Enferm USP 1998; 32(3):262-72.

(10) Marcus R, Bell DB. Occupational risk of human immunodeficiency virus infection in health care workers. In: deVita VT, Helman S, Rosemberg SA. Aids: etiology, diagnosis, treatment and prevention. $4^{\text {th }}$ ed. Philadelphia: Lippincott-Raven; 1997: p.645-54.
Evolução dos isolamentos em doenças transmissíveis: os saberes na prática contemporânea 
Lúcia Yasuko I. Nichiata Elucir Gir

Renata Ferreira Takahashi Suely Itsuko Ciosak
(11) Machado AA, Costa JC, Gir E, Moriya TM, Figueiredo FC. Risco de infecção pelo vírus da imunodeficiência humana (HIV) em profissionais da saúde. Rev Saude Publica 1992; 26(1):54-6.

(12) Canguilhem G. O normal e o patológico. Rio de Janeiro: Forense Universitária; 1978.

(13) Takahashi RF. A singularidade e a sociabilidade de vivenciar a "tuberculaids": a morte anunciada. [tese]. São Paulo (SP): Escola de Enfermagem da USP; 1997.

(14) Rosen G. Uma história da saúde pública. São Paulo: Hucitec; 1994.

(15) Czeresnia D. Do contágio à transmissão: ciência e cultura na gênese do conhecimento. Rio de Janeiro: Fiocruz; 1997.

(16) Waldman EA, Costa Rsosa TE. A dinâmica das doenças infecciosas. In: Saúde e Cidadania: vigilância de saúde pública. São Paulo: Instituto para o Desenvolvimento da Saúde; 1998, p.57-78.

(17) Foucault M. La crisis de la medicina o la crisis de la antimedicina. História de la medicalización del hospital en la tecnologia moderna. In: Medicina e história: el pensamiento de Michel Foucault. Washington: OPS; 1978.

(18) Nightingale F. Notas sobre enfermagem: o que é e o que não é. São Paulo: Cortez; 1989.

(19) Teixeira P, Valle S. Riscos biológicos em laboratório $\mathrm{s}$ de pesquisa. In: Teixeira $\mathrm{P}$, Valle $\mathrm{S}$. Biossegurança: uma abordagem multidis-ciplinar. Rio de Janeiro: Fiocruz: 1996, p.41-64.

(20) Organização Mundial da Saúde. Profilaxia das doenças transmissíveis. $9^{a}$.ed. São Paulo: Melhoramentos; 1960

(21) Benenson AS. Manual para el control de las enfermedades transmisibles. 16 ed. Brasília: OPS; 1997.

(22) Centro Latino-Americano e do Caribe de Informação em Ciências da Saúde. Decs: Descritores em Ciências da Saúde. São Paulo: BIREME; 2003. [on line] Disponível em $:<$ decs.bvs.br/cgi-bin/wxis 1660.exe/ decsserver/> (08 mai 2003).

(23) Garner JS. Guideline for Isolation Precautions in Hospitals: the hospital infection control practices advisory committee. Infect Control Hosp Epidemiol 1996; 17(4):214.

(24) CDC. Centers for Disease Control. Isolation techniques for use in hospitals. DHEW Publication, no. PHS, p. 70-2054, 1970.

(25) Garner JS, Simmons BP. CDC Guideline for Isolation Precautions in Hospitals. Atlanta: US Department of Health and Human Services. Public Health Service. Centers for Disease Control; 1983.
(26) CDC. Centers for Disease Control. Update: HIV infections in health-care workers exposed to blood of infected patients. Morb Mortal Wkly Rep 1987; 36(19):285-9.

(27) Ministério da Saúde. Centro de Documentação. Manual de controle de infecção hospitalar. Brasília. Centro de Documentação; 1985.

(28) Ministério da Saúde. Portaria nº . 196, de 24 de junho, 1983. Dispõe instruções para controle e prevenção das infecções hospitalares. Diário Oficial da República Federal do Brasil, Brasília, 28 jun. 1983. p.101.

(29) Ministério da Saúde. Secretaria Nacional de Vigilância Sanitária. Portaria $n^{\circ} .15$, de 23 de agosto, de 1988. Dispõe sobre a determinação de que o registro de produtos saneantes domissanitários com finalidade antimicrobiana seja procedido de acordo com as normas regulamentares anexas à presente. [online] Brasília (DF), 1988. Disponível em : <http://www.anvisa.gov.br/leis/portarias/ 15-18.htm> (14fev. 2002)

(30) Ministério da Saúde. Coordenação de controle de infecção hospitalar. Rev Control Infec Hosp 1994; 1:1-9.

(31) Ministério da Saúde. Manual de condutas. Exposição ocupacional a material biológico: hepatite e HIV. Brasília; 1999.

(32) Ministério da Saúde. Portaria n 2.616 de 12 de maio de 1998. Trata de ações de controle de infecção hospitalar no país. Diário Oficial da República Federativa do Brasil, Brasília, 13 mai 1998. Seção 1, p.133-5.

(33) São Paulo. (Estado). Informes Técnicos. Secretaria de Estado da Saúde. Isolamentos Hospitalares. São Paulo, n.15, 1991.

(34) São Paulo (Estado). Portaria CVS-11 de 4 de julho de 1995. Dispõe sobre as condições ideais de trabalho relacionadas ao controle de doenças transmissíveis em estabelecimentos de assistência odontológica. Diário Oficial do Estado de São Paulo, São Paulo, 5 jul. 1995, 105 (126):11-2.

(35) Arantes DV. Doenças transmissíveis: o percurso das práticas de isolamento. [dissertação] São Paulo(SP): Escola de Enfermagem da USP; 1997.

(36) Gir E, Takahashi RF, Oliveira MAC, Nichiata LYI, Ciosak SI. Biossegurança em DST/Aids: condicionantes da adesão do trabalhador de enfermagem às precauções. J Bras Doenças Sex Transm 2002; 14(3):117. [Apresentado no $4^{\circ}$ Congresso Brasileiro da Sociedade Brasileira de Doenças Sexualmente Transmissíveis; 2002 set 1-4; Manaus]. 